\title{
Working at sporting events
}

Working as a doctor at a sporting event can be both challenging and fun, so it is best to be prepared, finds Abi Rimmer

\section{Abi Rimmer}

The BMJ

\section{Think like a goalkeeper}

James S Thambyrajah, First5 lead GP for Royal College of General Practitioners South West Thames Faculty, says, "I have been a St Johns Ambulance volunteer doctor for eight years. I often work at Lords cricket ground and at the All England Lawn Tennis Club during Wimbledon. Over the years you naturally form bonds with colleagues. I often coordinate my shifts with paramedic friends as we have great rapport and, more importantly, we know how to work well as a team.

"I prepare for each job by adopting the mindset of a goalkeeper-maintaining focus throughout periods of stillness and sudden environmental changes. Often you need to spring into action for an 'on the line save' (an emergency). On my most recent shifts I had to manage a head injury, epistaxis, acute cholecystitis, seizures, and myocardial infarction.

"When working at a sporting event it helps to think about your work environment. For example, Wimbledon has 39000 spectators within the grounds at any one time. Therefore, I pay close attention to the morning team briefings because they're essential to gauge the number of patients we are likely to expect.

"I always review my advanced life support manual and algorithms in preparation for a shift. I became friends with the paramedics by being extra curious when they checked the defibrillators. I now do the checks myself because I like to ensure that every piece of equipment that I may use is in full working order. Working at these famous sporting arenas is always fun and rewarding - but be prepared, there is a lot of work involved in planning for a variety of challenging clinical scenarios."

\section{Read all the pre-event info}

Jodie Blackadder-Weinstein is a lecturer in general practice at the academic department of military general practice for the Royal Air Force, chair of the Royal College of General Practitioners' First5 national committee, educational lead for the British Society of Lifestyle Medicine, and academy doctor at Birmingham City Football Club.

She says, "When liaising with the event organisers it's important to be honest about your skill level to make sure you're working with a complimentary team. You might be a very senior surgical registrar with fantastic musculoskeletal knowledge, but when was the last time you delivered out-of-hospital cardiopulmonary resuscitation?

"Read any information that you receive. Many events will email you an info pack-read it. Some events will have set protocol for managing common presentations, or particular security procedures or reporting mechanisms that you will need to follow. It's also worth reading a bit about major incident management, so that when you see someone wandering around with 'bronze commander' emblazoned on their chest, you don't need to hide your bemusement.

"Research a bit of background on the event; what you would expect to see medically, as well as the logistics of the event itself. This can help alleviate any fears and focus your pre-reading. Core topics to read up on include exercise associated collapse, heat illness and hyponatraemia, and cardiac events. The Oxford Clinical Handbook of Sports and Exercise Medicine is my bible when it comes to all things sports medicine, supplemented with a frequent journal article review.

"Make sure you are indemnified. If volunteering, your indemnity provider will often cover you for a small fee or free, but you must inform them you are planning to support an event, and this should be annotated on your indemnity certificate.

"Finally, enjoy it. There is something special about being part of the inner workings of an event. Cheer on the participants, soak up the atmosphere, spot the odd celebrity_but keep your cool, asking for autographs is very much frowned upon."

\section{Get to know your environment}

Neeraj Bhasin, consultant vascular surgeon and associate medical director, Calderdale and Huddersfield NHS Foundation Trust, and previously permanent, now occasional, crowd doctor for Kirklees Stadium Development, Huddersfield, says, "Working at sporting events is a rewarding experience, which will see you treating varied conditions and using diverse skills in an unusual environment, as part of a multi-agency team.

"Practically, it is important to familiarise yourself with the environment you'll be working in. This could be a whole stadium, or a specific section. It is important to know where key areas are, such as the locations of certain stands or first aid rooms. It's also important to know the routes and methods of transporting casualties to a quiet area or first aid room, and where your first aid teams, paramedic team, and ambulances are situated. 
"It is useful to attend the medical or multi-agency briefing ahead of the event to understand the volume of people attending, any potential issues, and learn about any contingency plans from stadium management, police, fire, and medical teams. There may be a coded major incident warning message.

"Acquaint yourself with any equipment, such as defibrillators, and their location along with what you may personally carry. There will be non-medical equipment, such as radios for communication. Ensure you wear something practical. You should be given crowd doctor identification to enable access around the event.

"Financial arrangements differ depending on whether you are attending regularly or occasionally, or engaging through an event company or directly with the stadium. It is useful to notify your indemnity provider and make comprehensive contemporaneous medical notes, these should be kept locally by the stadium team. The patients are generally very grateful for the care they receive-so enjoy it!" 